\title{
Proportion of episodic memories from early childhood by years of age
}

\author{
HERBERT F. CROVITZ \\ Veterans Administration Hospital, Durham, North Carolina 27705 \\ and \\ KATHRYN QUINA-HOLLAND \\ University of Wisconsin-Milwaukee, Milwaukee, Wisconsin 53201
}

\begin{abstract}
Two experiments involving search through very long-term memory were conducted using Galton's method of semantic cuing. In the first experiment, 155 college students were asked to recall specific memories from their childhood associated with each of 12 English nouns. In Experiment II, 44 college students recalled 10-15 specific memories from their childhoods associated with a single cue noun. Students in both experiments then gave the age they were when each of the events had occurred. The proportion of memories from the years of early childhood thus obtained were compared to published data (Waldfogel, 1948) in which college students had been asked to recall and date all memories from before the age of 8 . The results were similar across the three studies, suggesting that the method of semantic cuing may be explored as an alternative to exhaustive free recall in attempts to measure the store of long-term episodic memory.
\end{abstract}

How can we measure the store of events that can be recalled, in order to learn more about the nature of episodic memory? One laborious method is exhaustive free recall. Waldfogel (1948) studied the store of memories from early childhood by having 124 college students write down all the memories they could recall that referred to events before they were eight years old. and to state as accurately as they could the age they were when the events occurred.

We used a method of semantic cuing in our research. a variant of Francis Galton`s (1879) original method. The purpose of this present work was to determine how valid this method is as compared to the time-consuming and laborious method of trying to exhaust the memory store in free recall used by Wald fogel.

Galton had studied his own store of episodic memories by forming associations to a list of words and noting the age of each association. Crovitz and Schiffman (1974) used a similar method, giving college students a list of English nouns with instructions to "think of a specific memory associated with each word." After completing the list. students noted the time elapsed since each of the recalled events had occurred. We have run two separate experiments based on the Crovitz and Schiffman method of semantic cuing. but have asked the students for memories from their childhood. This method was further changed to examine memories elicited by a single semantic cue. in Experiment II.

We thank Ray Horn and Harold Schiffman for helpful discussions. This work was supported by Project No. 1602-01 from the Veterans Administration Hospital, Durham. North Carolina.
We then compared the proportion of memories from before the age of 8 years ascribed to the various years of age obtained from these two studies to the data reported by Waldfogel in order to examine the validity of our methods as compared to Waldfogel.

\section{METHOD}

\section{Experiment 1}

Participants. Voluntary participants were 155 college students tested in a single group at the University of Wisconsin-Milwaukee. They received extra course credit for their participation.

Stimulus words. Cue words were 12 English nouns selected from the list of Paivio. Yuille, and Madigan (1968). They were: SAFETY. PRODUCT. SHIP. CLOCK. OWNER. TIME. BLESSING, AUTHOR, TABLE, BIRD, PRIDE, and INHABITANT.

Procedure. Students were given a test book let with instructions to "think of a memory from your childhood associated with each word" and to write a few words about each memory beside each cue word. After completing this section. they were instructed to return to each memory and to give. as accurately as possible. their chronological age when that event had taken place.

\section{Experiment 2}

Participants. With the same voluntary conditions as in Experiment 1. 44 college students were tested in smaller group sessions of 14-16 per session.

Stimulus words. Three cue words were utilized from the larger set of Experiment 1. They were: PRIDE. BIRD, and PRODUCT.

Procedure. Each participant was given a test sheet headed by a single cue word and was instructed to recall 10 to 15 specific memories from childhood associated with that noun. As in Experiment 1. the students dated all the events recalled.

\section{RESULTS}

Participants in Experiment I produced a total of only 755 memories dated before the age of 8 years. 


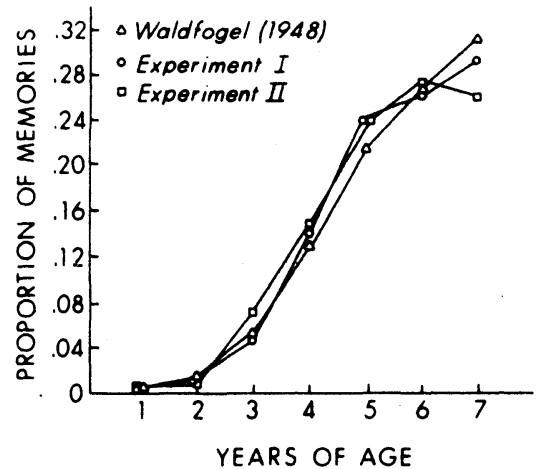

Figure 1. Distributions of early childhood memories.

Table 1

Correlations Between Three Sets of Data

\begin{tabular}{ccc} 
& Waldfogel's & Experiment \\
& Data & 2 \\
\hline Experiment 1 & $+.995^{* *}$ & $+.987^{* *}$ \\
Experiment 2 & $+.986^{* *}$ & \\
\hline
\end{tabular}

${ }^{* *} p<.001$

From Experiment 2, 172 such memories were obtained. We sought to compare these data to the findings of Waldfogel (1948) which were based on 6.487 memories dated before the age of 8 years. Since the question of interest in the present analysis is limited to the distribution of memories by year from before the age of 8 years, we discarded all memories from Experiment 1 and 2 dated from after the age of 7 years, and examined the proportion of the remaining memories by year. Thus, as in Waldfogel's study, we could examine memories from early childhood.

To simplify the comparison of the three sets of data, the proportion of memories ascribed to the years of age before age 8 was calculated for each set. These proportions are graphed in Figure 1. In none of the sets was there any memory ascribed to the time before the first birthday.

Correlations between the two sets of proportions obtained here and Waldfogel's data were extremely high and significant beyond the .001 level. Pearson product moment correlation coefficients were computed from arcsin transformation of the proportions and are shown in Table 1.

We also fitted the distributions to power curves, finding fairly similar results. For Waldfogel, $\mathrm{y}=.002 \mathrm{x}^{2.72}, \quad \mathrm{r}^{2}=.985 ;$ for Experiment $1, \mathrm{y}=$ $.003 \mathrm{x}^{2.53}, \quad \mathrm{r}^{2}=.946$, and for Experiment 2, $\mathrm{y}=.004 \mathrm{x}^{2} .35, \mathrm{r}^{2}=.880$, where $\mathrm{x}$ is years of age and $\mathrm{y}$ is the proportion of the memories reported before age 8.

\section{DISCUSSION}

The similarity of the data across the three studies suggests the method of semantic cuing and the method of exhaustive free recall tap the memory store in a similar way. However, both methods elicit recollections whose accuracy is not easily verified. This sharply differentiates these methods from those of Warrington and Silberstein (1970) and Squire and Slater (1975). Both studies limit memory probes to events widely known at various past times-their methods are to be preferred when the accuracy of very long-term memory is of interest. However, when interest is focused on the set of episodic recollections, semantic cuing may sometimes be preferable to the tedious method of exhaustive free recall.

\section{REFERENCES}

Crovitz, H. F., \& Schiffman, H. Frequency of episodic memories as a function of their age. Bulletin of the Psychonomic Society, 1974, 4, 517-518.

Galton, F. Psychometric experiments. Brain, 1879, 2, 148-162.

Paivio, A., Yuille, J. C., \& Madigan, S. A. Concreteness imagery, and meaningfulness values for 925 nouns. Journal of Experimental Psychology Monograph Supplement, 1968, 76. 1. 1-25.

SQUiRe, L. R., \& S SATER, P. C. Forgetting in very long-term memory as assessed by an improved questionnaire technique. Journal of Experimental Psychology: Human Learning and Memory, 1975, 1. 50-54.

Warrington, E. K., \& Silberstein, M. S. A questionnaire technique for investigating very long-term memory. Quarterly Journai of Experimental Psychology, 1970, 22, 508-512.

WALDFOGEL, S. The frequency and affective character of childhood memories. Psychological Monographs, 1948, 62, WHOLE No. 291.

(Received for publication October 2, 1975.) 